\title{
Cervical Arthroplasty for Traumatic Disc Herniation: An Age- and Sex-matched Comparison with Anterior Cervical Discectomy and Fusion
}

\author{
Hsuan-Kan Chang ${ }^{1,2}$, Wen-Cheng Huang ${ }^{1,2}$, Jau-Ching Wu $u^{1,2^{*}}$, Tsung-Hsi Tu ${ }^{1,2}$, Li-Yu Fay ${ }^{1,2}$, Peng-Yuan Chang ${ }^{1,2}$, \\ Ching-Lan Wu $\mathrm{U}^{2,4}$, Huang-Chou Chang ${ }^{5}, \mathrm{Yu}$-Chun Chen ${ }^{2,6,7}$ and Henrich Cheng ${ }^{1,2,3}$
}

\begin{abstract}
Background: The efficacy and safety of using cervical arthroplasty for degenerative disc disease have been demonstrated by prospective, randomized and controlled clinical trials. However, there are scant data on using cervical arthroplasty for traumatic disc herniation. Therefore, this study aimed to investigate the outcomes of patients who underwent cervical arthroplasty for traumatic disc herniation.
\end{abstract}

Methods: This cohort included patients who were admitted through the emergency department for trauma. Only patients who had newly-onset, one- or two-level cervical disc disease causing radiculopathy or myelopathy were identified. None of these patients had previously sought for medical attention for such problems. Those patients who had severe spinal cord injury (i.e. American Spinal Injury Association scale A, B or C) or severe myelopathy (i.e. Nurick scale 4 or 5), bony fracture, dislocation, perched facet, kyphotic deformity, or instability were also excluded. An age- and sex-matched one-to-one comparison was made between patients who underwent cervical arthroplasty, on the one hand, and anterior cervical discectomy and fusion (ACDF).

Results: A total of 30 trauma patients (15 in the arthroplasty group and 15 in the ACDF group) were analyzed, with a mean follow-up of 29.6 months. The demographic data were similar. Post-operation, the arthroplasty group had significant improvement in VAS of neck and arm pain, JOA, and NDI when compared to their pre-operation status. Similarly, the ACDF group also improved significantly after the operation. There were no differences between the two groups in post-operative VAS neck and arm pain, and JOA scores. The arthroplasty group maintained a range of motion in the indexed levels and had better NDI scores at 6-months post-operation than the ACDF group.

Conclusions: For selected patients (i.e. no spinal cord injury, no fracture, and no instability) with traumatic cervical disc herniation, cervical arthroplasty yields similar improvement in clinical outcomes to ACDF and preserves segmental mobility.

\section{Background}

The efficacy and safety of using cervical arthroplasty for degenerative disc disease (DDD) have been demonstrated by several prospective, randomized and controlled studies by the United States Food and Drug Administration Investigational Device Exemption (FDA-IDE) trials [1-10]. These trials enrolled patients with cervical DDD or

\footnotetext{
* Correspondence: jauching@gmail.com

'Department of Neurosurgery, Neurological Institute, Taipei Veterans General Hospital, Room 508, 17F, No. 201, Shih-Pai Road, Sec. 2, Beitou, Taipei 11217, Taiwan

${ }^{2}$ School of Medicine, National Yang-Ming University, Taipei, Taiwan

Full list of author information is available at the end of the article
}

spondylosis causing radiculopathy, myelopathy, or both, and demonstrated that the clinical outcomes were similar at two to eight years of follow up for both cervical arthroplasty and anterior cervical discectomy and fusion (ACDF) [11]. However, there are scant data in the literature on using cervical arthroplasty for traumatic disc herniation. In the opinion of several experts, cervical trauma causing ligamentous or bony injury has been listed as a contraindication for cervical arthroplasty [12-14]. Nevertheless, it is not uncommon to see patients with symptomatic disc disease after minor neck injury. Although there are inadequate data, cervical arthroplasty may be an option for

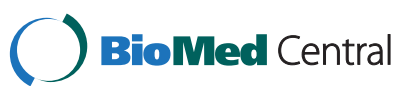

(C) 2015 Chang et al. Open Access This article is distributed under the terms of the Creative Commons Attribution 4.0 International License (http://creativecommons.org/licenses/by/4.0/), which permits unrestricted use, distribution, and reproduction in any medium, provided you give appropriate credit to the original author(s) and the source, provide a link to the Creative Commons license, and indicate if changes were made. The Creative Commons Public Domain Dedication waiver (http://creativecommons.org/publicdomain/zero/1.0/) applies to the data made available in this article, unless otherwise stated. 
these patients who had no spinal cord injury, fracture, or instability, but mainly disc disease.

Anterior cervical discectomy has been commonly accepted as the management of neural tissue compression caused by disc herniation, albeit degenerative or traumatic [15-19]. For patients with trauma, ACDF could not only replace the broken disc but also provide immediate fixation by application of plate and screws, whereas cervical arthroplasty provides less immediate stability post-operatively. Therefore, it is clear that traumatic disc herniation coexisting with instability such as fracture, dislocation, or compromised posterior ligamentous complex would definitely require ACDF rather than arthroplasty. On the other hand, in a carefully selected patient-for example, a young person who experienced minor neck trauma while playing sport and who had no instability or facet joint disease but a traumatic disc herniation causing myelo-radiculopathy that warranted anterior cervical discectomy-cervical arthroplasty might be a reasonable alternative to conventional ACDF. There are reports addressing adjacent segment disease (ASD) after $\mathrm{ACDF}$ as well as subsequent secondary surgery [20, 21]. Moreover, these male and younger patients who have a higher risk of trauma are also of higher chances of ASD and the re-operations [21]. Therefore, cervical disc arthroplasty might be particularly valuable for these trauma patients if it reduces the development of ASD. Although this potential advantage has not yet been proven by the currently available clinical trials for degenerative disc disease, it is reasonable to expect some differences in the setting of trauma, which could accelerate the pathology of ASD.

This study aimed to investigate the outcomes of patients who underwent cervical arthroplasty for traumatic disc herniation. The FDA-IDE trials comparing arthroplasty to ACDF did not specifically look into these patients.

\section{Methods}

\section{Study design}

Medical records, images and neurological evaluations of our institute were retrospectively reviewed. All patients who had neurosurgical consultation and were admitted through the emergency department of our institute for cervical spinal trauma, from May 2007 to December 2011, were identified. The inclusion criteria were patients with one- or two-level traumatic cervical disc herniation who required and received anterior cervical discectomy and either arthroplasty or ACDF. None of these patients had previously sought for medical attention for such problems. In other words, only those patients who had not had radiculopathy and myelopathy seeking medical attention previously were included. Thus the cervical disc disease was most likely related to the trauma event rather than degeneration. The exclusion criteria were: (1) severe spinal cord injury equal to or worse than the American Spinal Cord Injury Association (ASIA) impairment scale C (i.e. ASIA scale A, B and C); (2) severe cervical myelopathy (i.e. Nurick scale 4 or 5); (3) bony fracture or evident segmental instability (i.e. more than $3.5 \mathrm{~mm}$ translation or $20^{\circ}$ angular motion) at the indexed level; (4) segmental arthrodesis without mobility; (5) incompetent facet joints;(6) adjacent segment disease after previous cervical fusion; (7) ossification of posterior longitudinal ligament (OPLL), or (8) kyphotic deformity. Patients who underwent previous cervical spine surgery or had disc disease at more than two levels were also excluded.

Each of the patients fulfilling the above mentioned criteria and who underwent one- or two-level cervical arthroplasty was compared to one age- and sex-matched patient who underwent ACDF for a similar condition during the same period of time. All the demographic data, operation notes, peri-operative medical records, clinical outcomes, and radiographic evaluations were analyzed. Written informed consent was obtained from participants, and the Institutional Review Board, Taipei Veterans General Hospital, approved the study.

\section{Surgical technique}

For cervical arthroplasty, the patient was placed in a supine position under general anesthesia. A right-sided horizontal incision along the skin crease in the neck was made correlating to the target level of the cervical disc. Intra-operative fluoroscopy was used to confirm the target level(s). Generous decompression of the bilateral neuroforamen was performed after discectomy with resection of bilateral uncovertebral joints. Resection of the posterior longitudinal ligament was routinely performed on every patient to ensure adequate decompression of the spinal cord. Copious saline irrigation was applied during the whole procedure of drilling of the osteophytes and milling of the endplates. We aimed to achieve optimal carpentry of the cervical arthroplasty by meticulous endplate preparation and appropriate sizing of the artificial disc [22]. One of two kinds of arthroplasty devices, a Bryan disc (Medtronic, Memphis, TN) or Prestige LP (Medtronic, Memphis, TN) artificial disc, was implanted in this series of patients under guidance of intraoperative fluoroscopy. A closedsystem drainage catheter was then placed and the wound was closed layer by layer in every patient.

For ACDF patients, the surgical approach and techniques of decompression were very similar to that used for arthroplasty patients. All ACDF procedures used interbody cages and were instrumented with titanium cervical plates and screws. 
Evaluation of clinical outcomes and radiographic studies

Standardized clinical outcomes, including visual analogue scale (VAS), neck disability index (NDI), and Japanese Orthopedic Association (JOA) scores, were collected at each time-point for follow-up post-operation, at approximately 6, 12 and 24 months. Data were collected by two special nurse assistants under the physicians' supervision during clinic visits.

Standard anterior-posterior/lateral and lateral flexion/ extension radiographs were taken at each time-point mentioned above. Radiographic reports and range of motion (ROM) at target level(s) were interpreted and measured using the PACS system software, SmartIris (Taiwan Electronic Data Processing Co., Taiwan) on a medical-use screen by independent radiologists or surgeons. ROM was measured on dynamic lateral radiographs. Angulation of arthroplasty was determined using Cobb criteria as same as one of the FDA-IDE trials [6]. Repeated measurement was undertaken, and a final decision was made by the senior author of this study if there was any discrepancy in the interpretation or measurement.

\section{Statistical analysis}

Independent $t$-tests and paired $t$-tests were used for data analysis using the SPSS Software (SPSS Inc., Chicago, USA). The statistical significant value was defined as $p$-value of $<0.05$.

\section{Results}

Identification of patients with traumatic disc herniation

During the study period, only patients who were admitted via the emergency department of our institute for cervical spine trauma were qualified as candidates for further analysis. The surgeons were neutral to both the surgical approaches and provided the patients as well as the family with equally adequate information for both the ACDF and cervical arthroplasty. The eventual choice of ACDF or cervical arthroplasty was made upon their preference. Both types of surgery were equally priced by the National Health Insurance of Taiwan, which has universal coverage. Theoretically, there was little selection bias from the surgeons' aspect.

A total of 16 patients fulfilled the inclusion criteria described above and underwent one- or two-level cervical arthroplasty. Among them, 15 (94\%) patients completed the scheduled follow-ups and were thus analyzed as the arthroplasty group. For each patient in the arthroplasty group, one age- and sex-matched patient who received ACDF was selected from the cohort for comparison.

\section{Demographic data}

Owing to the specifically tailored comparison (i.e. matching age and gender), there were little differences in the demographic data between both groups (Table 1).
Table 1 Comparison of the demographic data

\begin{tabular}{llll}
\hline & Arthroplasty & ACDF & $p$ value \\
\hline No. of patients & 15 & 15 & \\
Age (years) & $48.8 \pm 9.3$ & $53.6 \pm 12.3$ & 0.234 \\
Gender & & & \\
$\quad$ Male & 11 & 11 & \\
$\quad$ Female & 4 & 4 & \\
$\quad$ Mean operation time (min) & $214.3 \pm 56.8$ & $200.6 \pm 58.1$ & 0.52 \\
Pre-op ROM (degree) & & & \\
$\quad$ Mean & $5.3 \pm 1.6$ & $7.4 \pm 3.6$ & 0.113 \\
Cigarette smoking & 3 & 3 & 1.00 \\
Diabetes & 2 & 2 & 1.00 \\
Hypertension & 4 & 5 & 0.694 \\
End-stage renal disease & 0 & 0 & 1.00 \\
\hline
\end{tabular}

$R O M$ : range of motion at the indexed levels

Among the 15 patients of the arthroplasty group, there were $11(73.3 \%)$ males and $4(26.6 \%)$ females, and the mean age was $48.8 \pm 9.3$ years. The mean follow-up time was $29.6 \pm 9.1$ months. The segmental mobility was similar in both groups prior to the operation (mean range of motion:5.3 \pm 1.6 and 7.4 $\pm 3.6, p=0.113$, the arthroplasty and the ACDF groups, respectively). Furthermore, both groups had similar rates of underlying medical conditions, including cigarette smoking, diabetes, hypertension, and end-stage renal disease requiring hemodialysis.

The level distribution of the arthroplasty and the ACDF groups are demonstrated in Table 2. The most frequently injured level was C5/6 (47.6 \%) in the arthroplasty group, and C4/5 (40\%) in the ACDF group, respectively.

\section{Cervical arthroplasty versus ACDF}

Clinical and radiographic outcomes were compared between the two groups (Table 3). The mean operation time between the two groups had no significant

Table 2 Level distributions

\begin{tabular}{ll}
\hline Level & No. of level \\
\hline Arthroplasty (Total level =21) & \\
C3/4 & $5(23.8 \%)$ \\
C4/5 & $4(19.0 \%)$ \\
C5/6 & $10(47.6 \%)$ \\
C6/7 & $2(9.5 \%)$ \\
ACDF (Total level =25) & \\
C3/4 & $4(16.0 \%)$ \\
C4/5 & $10(40.0 \%)$ \\
C5/6 & $8(32.0 \%)$ \\
C6/7 & $3(12.0 \%)$ \\
\hline
\end{tabular}


Table 3 Comparison of the outcome measurements

\begin{tabular}{llll}
\hline & $\begin{array}{l}\text { Arthroplasty } \\
(n=15)\end{array}$ & $\begin{array}{l}\text { ACDF } \\
(n=15)\end{array}$ & $p$ value \\
\hline Operation time (min) & $214.3 \pm 56.8$ & $200.6 \pm 58.1$ & 0.52 \\
Estimated blood loss (ml) & $94.1 \pm 102.0$ & $128.1 \pm 125.3$ & 0.56 \\
Post op neck pain VAS & $1.7 \pm 2.0$ & $1.0 \pm 1.4$ & 0.38 \\
Post op arm pain VAS & $1.5 \pm 2.1$ & $1.1 \pm 1.3$ & 0.63 \\
Post op ROM & $6.2 \pm 5.0$ & $0.5 \pm 0.4$ & $0.002^{*}$ \\
Rate of HO & $40 \%(n=6)$ & - & - \\
\hline
\end{tabular}

$R O M$ : range of motion, $H O$ : heterotopic ossification

${ }^{*} p<0.05$, statistically significant

difference $(214.3 \pm 56.8$ versus $200.6 \pm 58.1 \mathrm{~min}, p=$ 0.52). The mean estimated blood loss (EBL) also had no significant difference $(94.1 \pm 102.0$ vs. $128.1 \pm 125.3 \mathrm{ml}$, $p=0.56)$ between the two groups. The post-operative range of motion (ROM) at the index level was significantly different $\left(6.2 \pm 5.0\right.$ vs. $\left.0.5 \pm 0.4^{\circ}, p=0.002\right)$. The arthroplasty successfully preserved mobility at the indexed level of the cervical spine, whereas ACDF achieved arthrodesis.

In the arthroplasty group every parameter of the clinical outcomes, including VAS neck, VAS arm, NDI, and JOA scores, demonstrated significant improvement after the operation when compared to pre-operation (Figs. 1, 2 and 3). The improvement in these clinical outcomes were similar between the arthroplasty group and the ACDF group at 6-, 12- and 24-months post-operation (Figs. 4, 5 and 6), except that the arthroplasty group had significantly better NDI scores than the ACDF group at 6 months post-operation $(p=0.049)$ (Fig. 5).

In the present series of patients there was no secondary surgery (i.e. re-operation, revision, removal of implant, or conversion of arthroplasty to fusion), no surgical complications (i.e. spinal cord injury, permanent

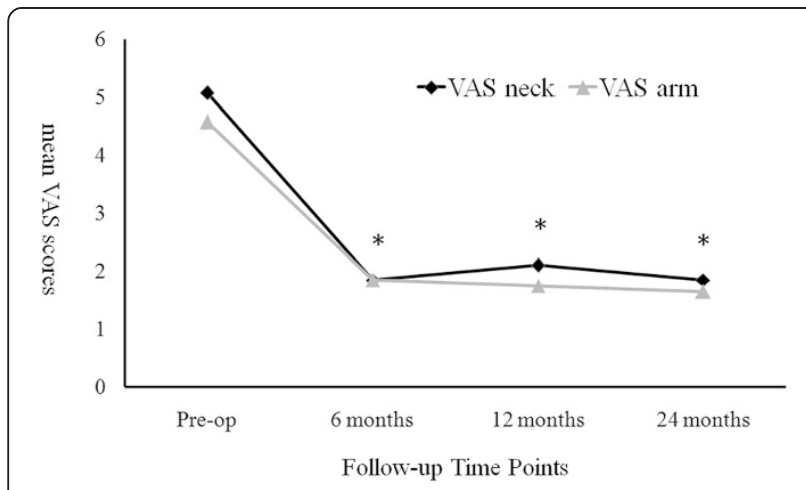

Fig. 1 Comparison of mean neck and arm VAS scores in the arthroplasty group $(n=15)$. Significant improvement after surgery was noted for both neck and arm pain at each follow-up time point (i.e. post-operative 6, 12 and 24 months). Asterisk, $p$-value $<0.05$ compared to pre-operative scores

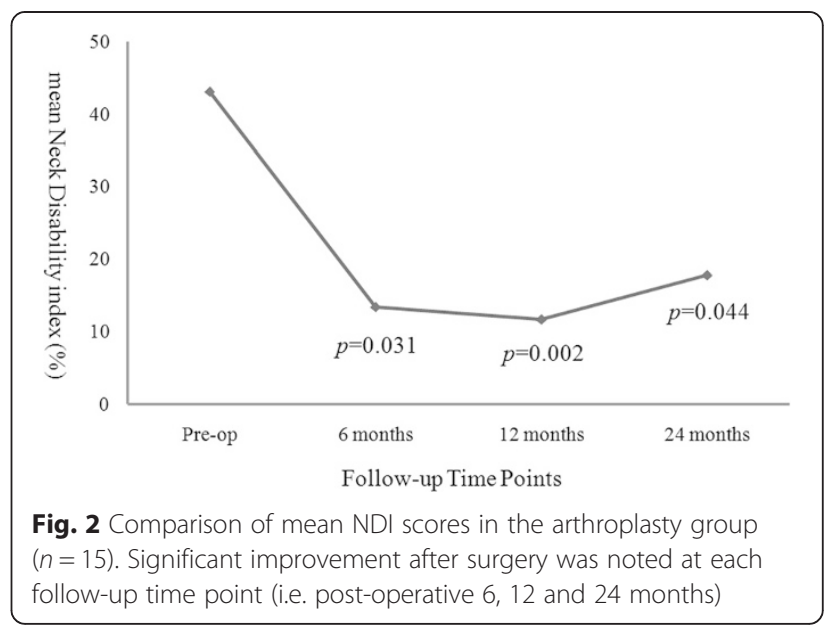

dysphagia or hoarseness, wound infection, or postoperative hematoma). In addition, there was no adjacent segment disease (ASD) that required surgery to date.

\section{Discussion}

The FDA trials of cervical arthroplasty enrolled patients with 1- and 2-level cervical disc disease but did not specifically look into the disc herniation caused by minor cervical spinal trauma [1-6, 8, 9]. Since ACDF has been widely accepted as the gold standard surgical approach following neck trauma, those symptomatic patients who require anterior cervical discectomy could definitely be treated by ACDF. However, in selected patients-for example, those young patients who have no spinal cord injury, fracture or instability-cervical arthroplasty may be a viable alternative [23-25]. The present study analyzed 30 patients with traumatic cervical disc herniation who were admitted via the emergency department due to neck injury and who underwent anterior cervical discectomy subsequently. Among these 30 patients, the authors

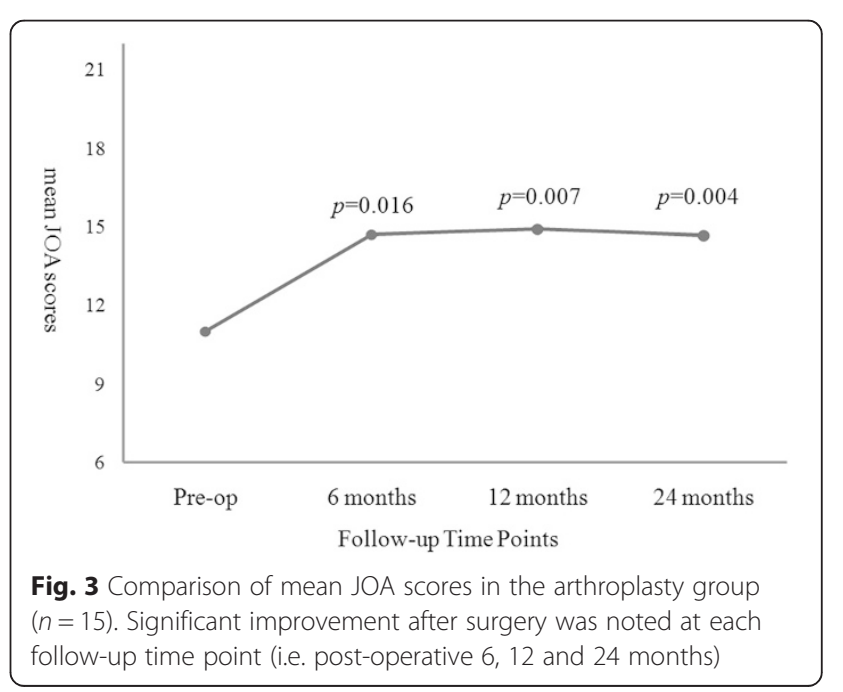




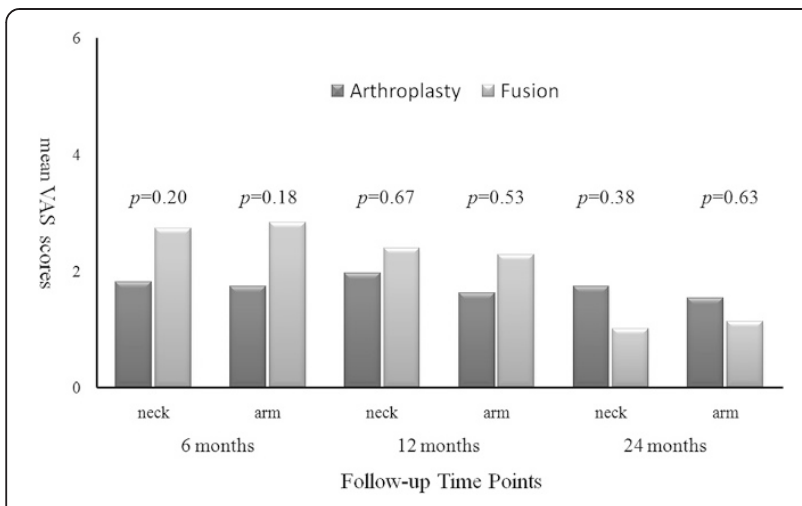

Fig. 4 Comparison of mean neck and arm VAS scores between arthroplasty $(n=15)$ and fusion $(n=15)$ groups. No significant difference was noted between the two groups at each follow-up time point (i.e. post-operative 6,12 and 24 months)

conducted a head-to-head comparison (age- and sexmatched) between cervical arthroplasty and ACDF. Significant improvement in clinical outcomes, including VAS neck, VAS arm, JOA and NDI scores, were demonstrated post-operatively for both the arthroplasty and the ACDF groups. Furthermore, there were little differences in clinical outcomes between the two groups. The demographic characteristics, operation time, and co-morbidities were similar between the two groups. Therefore, the results of this series demonstrate that cervical arthroplasty is a viable option in carefully selected patients with minor cervical trauma. Younger patients who had no spinal cord injury, no bony fracture, and no ligamentous injury causing instability are likely good candidates for cervical arthroplasty.

Cervical spine trauma can range from minor sprain to catastrophic spinal cord injuries [26]. It is widely accepted that ACDF or anterior cervical corpectomy and

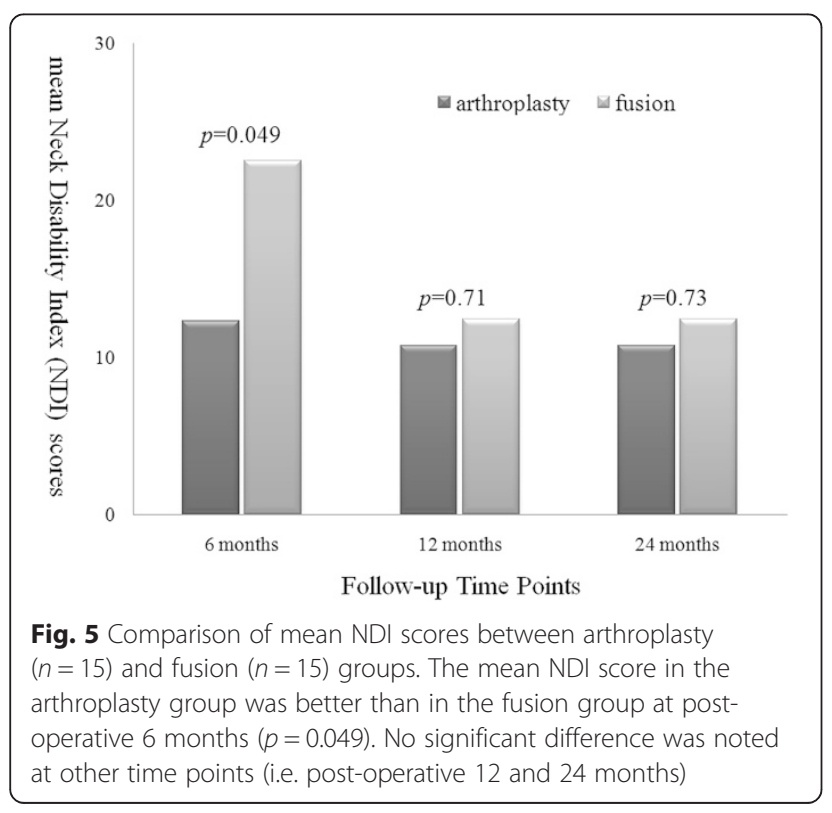

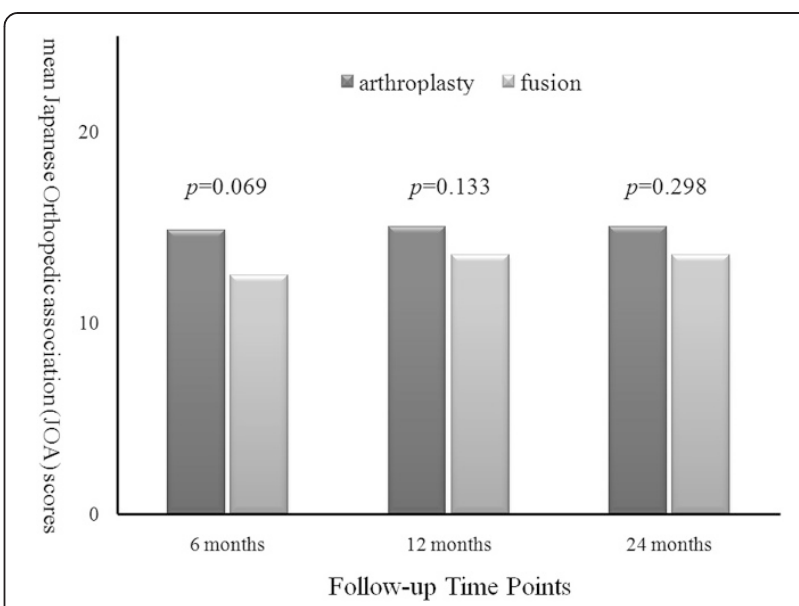

Fig. 6 Comparison of mean JOA scores between arthroplasty $(n=15)$ and fusion ( $n=15)$ groups. No significant difference was noted between the two groups at each follow-up time point (i.e. postoperative 6, 12 and 24 months)

fusion (ACCF) is the gold standard management procedure for trauma-related $\mathrm{C}$ spine injury including HIVD, fracture, locked facet, or dislocation, etc [26-29]. In the instance of some disastrous cases, combined anterior and posterior decompression with instrumentation is imperative for $360^{\circ}$ circumferential fixation [30]. The recent literature regarding non-catastrophic traumatic cervical disc herniation without fracture, dislocation or spinal instability were mostly about athletes $[26,28,29,31]$. The postoperative clinical outcomes were good with ACDF despite some late morbidities of fusion that were reported. Maroon et al. reported two out of five ( $40 \%$ ) patients developed adjacent segment degeneration (ASD) [28]. They also concluded that ASD was an inherent risk after ACDF in a series of 15 traumatic patients [26]. Although there is still inadequate evidence to support the reduction of ASD by cervical arthroplasty, it has been adopted worldwide for more than a decade with excellent results for one- and two-level DDD and spondylosis [3, 5, 6, 9] The best candidates for cervical arthroplasty are young patients with medical refractory radiculopathy caused by soft disc herniation who require anterior cervical discectomy, because cervical arthroplasty relieves neurological symptoms while preserving mobility, and might potentially decrease ASD $[24,25,32,33]$ It is therefore reasonable to infer that patients with mild cervical spinal trauma causing disc herniation (i.e. patients who had no bony fracture or instability but soft disc herniation) can be managed by cervical arthroplasty. However, it must be emphasized that patients with any more severe spinal trauma, for example, severe myelopathy (i.e. Nurick scale 4 or 5) or spinal cord injury worse than ASIA-D, kyphotic deformity, facet incompetence, inadequate integrity of the posterior element, or obvious instability, are definitely contraindicated for arthroplasty. 
Postoperative stability is a challenge of cervical arthroplasty for trauma. Obviously, patients with fracture or dislocation should not be considered as candidates of arthroplasty. The relative contraindications of cervical arthroplasty also include incompetent posterior elements and ligamentous injury. In the current series, cervical arthroplasty successfully preserved mobility at the indexed level, whereas instrumented ACDF successfully achieved arthrodesis. On dynamic radiographs, the post-operative ROM was individually compared to that of pre-operation at each index level in this study. In the arthroplasty group, the post-operative $\mathrm{ROM}$ was preserved when compared to that of pre-operation $\left(6.2 \pm 5.0\right.$ vs. $\left.5.3 \pm 1.6^{\circ}\right)$ (Figs. 7 and 8). This preservation of mobility at each index level of cervical arthroplasty was compatible to the measurement in those FDA trials (approximately $7^{\circ}$ ) [8]. On the other hand, the intended arthrodesis was achieved in the ACDF group with the application of plate and screw fixation (mean post-operative ROM: $0.5 \pm 0.4^{\circ}$ versus preoperation at $\left.7.4 \pm 3.6^{\circ}\right)$. The concern for immediate stability after the operation might be an issue initially in the arthroplasty group. However, the patients who received arthroplasty had similar VAS neck pain scores to those who received ACDF at 6-, 12 and 24-months post-operation. Patients in both groups had significant improvement in neck pain. There were no implant failures, migrations, or dislodgements in the current series. Therefore, this result can indirectly attenuate doubts of stability in traumatic disc herniation, under the premises that there was little ligamentous injury.

There were limitations to this study. First, there was inherent selection bias due to the fact that this was a retrospective, non-randomized study. The choices between arthroplasty and ACDF were based on both the surgeons' and the patients' preferences. Although both options were equally presented and explained to the patient and family upon consultation at the emergency department, it was possible that the choice could be deviated by economic issues or subjective interpretation. Second, the diagnosis of ligamentous injury for exclusion was not always easy. Patients would have been excluded from the current series if there was evidence of disc rupture and destruction of the anterior longitudinal ligament on the preoperative magnetic resonance images. Greater than $3.5 \mathrm{~mm}$ translation or $20^{\circ}$ angular motion found on the flexion-extension lateral radiographs would also have been excluded. However, it was possible that patients with strong neck muscles or moderate spondylosis could limit the detection of laxity or segmental instability after injury. Therefore, the study used the most stringent criteria to include only those trauma cases with minor neck injury. Third, the relatively small sample size could limit the power of this study. Due to the narrow inclusion criteria and at least two years of follow-up, there were not so many cases of minor cervical injury. Nevertheless, the authors compared these specific trauma cases of arthroplasty to the gold standard surgical treatment of ACDF. Moreover, the age- and sex-matched comparison could further reduce the heterogeneity of this cohort.

In summary, this was the first study on the application of cervical arthroplasty in trauma patients who developed disc herniation but little bone and nerve injury. The study could shed light on the indication of cervical arthroplasty for trauma. Future studies are definitely required to corroborate the results and push the envelope of the technology of cervical arthroplasty.

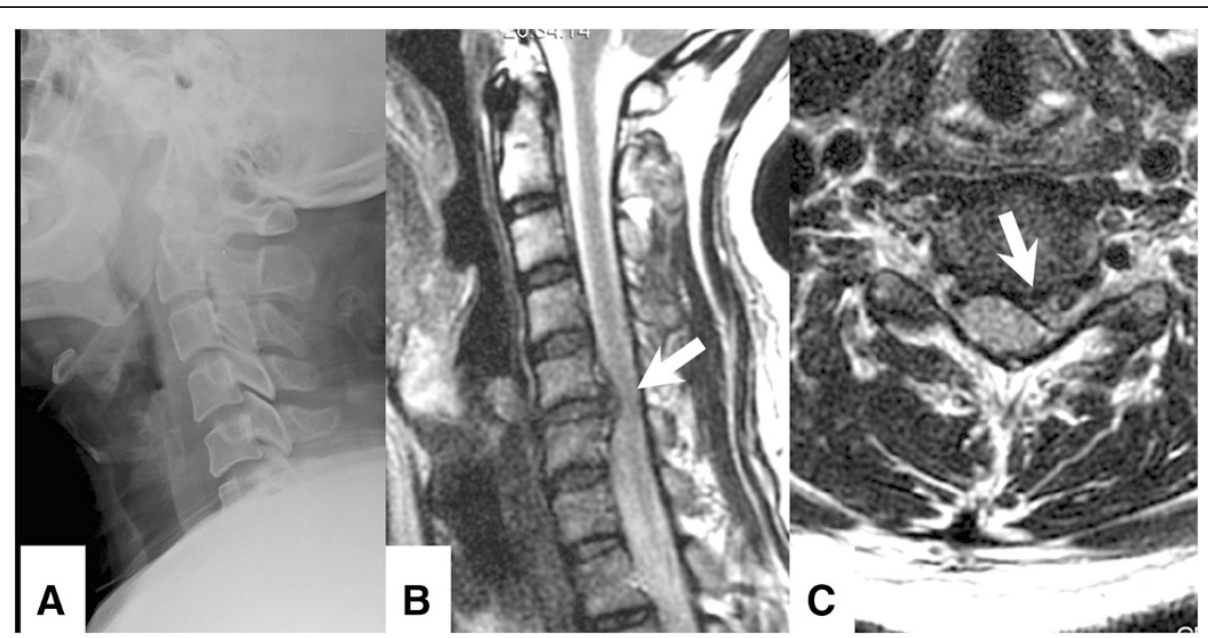

Fig. 7 Illustration case of traumatic cervical disc herniation. Pre-operative lateral radiographs (a) and MRI T2-weighted image (b: sagittal view, and c: axial view) of a 46-year-old male with traumatic cervical disc herniation who underwent Prestige LP arthroplasty at C5-6. A trauma-related ruptured disc at left C5-6 level was seen (b and c, white arrow) 


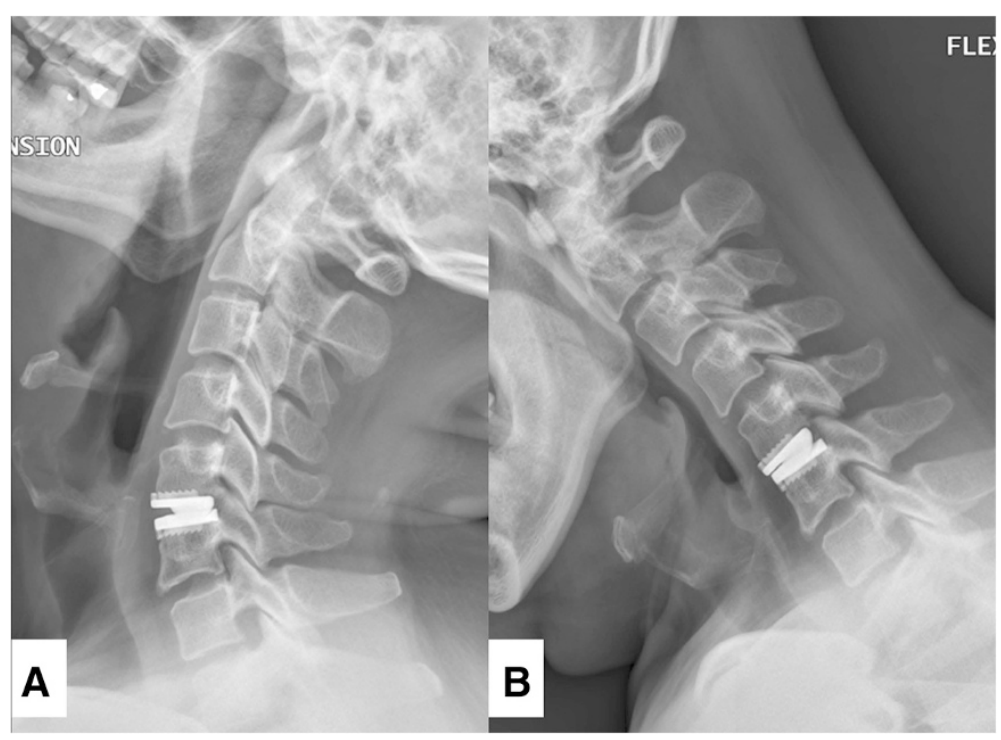

Fig. 8 Post-operative dynamic lateral films of the patient mentioned in Fig. 7. The X-ray image demonstrated that the treated levels remained mobile at 24-months follow-up (a: extension, and $\mathbf{b}$ : flexion)

\section{Conclusion}

For selected patients (i.e. no spinal cord injury, no fracture, and no instability) with traumatic cervical disc herniation, cervical arthroplasty yields similar improvement in clinical outcomes to ACDF and preserves segmental mobility.

\section{Abbreviations \\ ACDF: Anterior cervical discectomy and fusion; DDD: Degenerative disc disease; FDA-IDE: Food and Drug Administration Investigational Device Exemption; ASIA: American Spinal Cord Injury Association; OPLL: Ossification of posterior longitudinal ligament; VAS: Visual analogue scale; NDI: Neck disability index; JOA: Japanese Orthopedic Association; ROM: Range of motion; ASD: Adjacent segment disease; ACCF: Anterior cervical corpectomy and fusion; HIVD: Herniated intervertebral disc.}

\section{Competing interests}

The authors declare that they have no competing interests.

\section{Authors' contributions}

HKC, WCH, and JCW have made contributions to conception and design, or acquisition of data, or analysis and interpretation of data, writing the manuscript. TH T, LYF, PYC, and YCC have contributed in drafting the manuscript or revising it critically for important intellectual content. CLW, HCC, and HC have contributed in design, interpretation of data, and critically revising the manuscript. All authors reviewed and approved the final version of the manuscript.

\section{Acknowledgment}

This article did not receive any form of pharmaceutical or industry support.

\section{Author details}

'Department of Neurosurgery, Neurological Institute, Taipei Veterans General Hospital, Room 508, 17F, No. 201, Shih-Pai Road, Sec. 2, Beitou, Taipei 11217 , Taiwan. ${ }^{2}$ School of Medicine, National Yang-Ming University, Taipei, Taiwan. ${ }^{3}$ Institute of Pharmacology, National Yang-Ming University, Taipei, Taiwan. ${ }^{4}$ Department of Radiology, Taipei Veterans General Hospital, Taipei, Taiwan. ${ }^{5}$ Department of Surgery, Kaohsiung Veterans General Hospital, Kaohsiung, Taiwan. ${ }^{6}$ Department of Medical Research and Education, National Yang-Ming University Hospital, I-Lan, Taiwan. ${ }^{7}$ Institute of Hospital and Health
Care Administration, National Yang-Ming University School of Medicine, Taipei, Taiwan.

Received: 7 February 2015 Accepted: 20 August 2015

Published online: 28 August 2015

\section{References}

1. Burkus JK, Haid RW, Traynelis VC, Mummaneni PV. Long-term clinical and radiographic outcomes of cervical disc replacement with the Prestige disc: results from a prospective randomized controlled clinical trial. J Neurosurg Spine. 2010;13(3):308-18. doi:10.3171/2010.3.SPINE09513.

2. Coric D, Kim PK, Clemente JD, Boltes MO, Nussbaum M, James S. Prospective randomized study of cervical arthroplasty and anterior cervical discectomy and fusion with long-term follow-up: results in 74 patients from a single site. J Neurosurg Spine. 2013;18(1):36-42. doi:10.3171/2012.9.SPINE12555.

3. Coric D, Nunley PD, Guyer RD, Musante D, Carmody CN, Gordon CR, et al. Prospective, randomized, multicenter study of cervical arthroplasty: 269 patients from the Kineflex C artificial disc investigational device exemption study with a minimum 2-year follow-up: clinical article. J Neurosurg Spine. 2011;15(4):348-58. doi:10.3171/2011.5.SPINE10769.

4. Davis RJ, Kim KD, Hisey MS, Hoffman GA, Bae HW, Gaede SE, et al. Cervical total disc replacement with the Mobi-C cervical artificial disc compared with anterior discectomy and fusion for treatment of 2-level symptomatic degenerative disc disease: a prospective, randomized, controlled multicenter clinical trial: clinical article. J Neurosurg Spine. 2013;19(5):532-45. doi:10.3171/2013.6.SPINE12527.

5. Heller JG, Sasso RC, Papadopoulos SM, Anderson PA, Fessler RG, Hacker RJ, et al. Comparison of BRYAN cervical disc arthroplasty with anterior cervical decompression and fusion: clinical and radiographic results of a randomized, controlled, clinical trial. Spine (Phila Pa 1976). 2009;34(2):101-7. doi:10.1097/BRS.0b013e31818ee263.

6. Mummaneni PV, Burkus JK, Haid RW, Traynelis VC, Zdeblick TA. Clinical and radiographic analysis of cervical disc arthroplasty compared with allograft fusion: a randomized controlled clinical trial. J Neurosurg Spine. 2007;6(3):198-209. doi:10.3171/spi.2007.6.3.198.

7. Quan GM, Vital JM, Hansen S, Pointillart V. Eight-year clinical and radiological follow-up of the Bryan cervical disc arthroplasty. Spine (Phila Pa 1976). 2011;36(8):639-46. doi:10.1097/BRS.0b013e3181dc9b51.

8. Upadhyaya CD, Wu JC, Trost G, Haid RW, Traynelis VC, Tay B, et al. Analysis of the three United States Food and Drug Administration investigational device exemption cervical arthroplasty trials. J Neurosurg Spine. 2012;16(3):216-28. doi:10.3171/2011.6.SPINE10623. 
9. Murrey D, Janssen M, Delamarter R, Goldstein J, Zigler J, Tay B, et al. Results of the prospective, randomized, controlled multicenter Food and Drug Administration investigational device exemption study of the ProDisc-C total disc replacement versus anterior discectomy and fusion for the treatment of 1-level symptomatic cervical disc disease. Spine J. 2009;9(4):275-86. doi:10.1016/j.spinee.2008.05.006.

10. Sasso RC, Anderson PA, Riew KD, Heller JG. Results of cervical arthroplasty compared with anterior discectomy and fusion: four-year clinical outcomes in a prospective, randomized controlled trial. J Bone Joint Surg Am. 2011;93(18):1684-92. doi:10.2106/JBJS.J.00476.

11. Cappelletto B, Giorgiutti F, Veltri C, Trevigne MA, Facchin P, Del Fabro P. Disc prosthesis replacement and interbody fusion in the treatment of degenerative cervical disc disease: comparative analysis of 176 consecutive cases. Eur Spine J. 2013;22 Suppl 6:S894-9. doi:10.1007/s00586-013-3023-y.

12. Wu JC. Cervical total disc replacement. Formosan J Surg. 2014;47(2):49-52. http://dx.doi.org/10.1016/j.jjs.2013.07.005

13. Wu JC, Meyer SA, Gandhoke G, Mummaneni PV. PRESTIGE Cervical Arthroplasty: Past, Present, and Future. Seminars in Spine Surgery. 2012;24(1):14-9. doi:10.1053/j.semss.2011.11.004.

14. Mummaneni PV, Robinson JC, Haid Jr RW. Cervical arthroplasty with the PRESTIGE LP cervical disc. Neurosurgery. 2007;60(4 Suppl 2):310-4. doi:10.1227/01.NEU.0000255376.42099.13. discussion 4-5.

15. Sonntag VK, Han PP, Vishteh AG. Anterior cervical discectomy. Neurosurgery. 2001;49(4):909-12.

16. Shapiro S, Connolly P, Donnaldson J, Abel T. Cadaveric fibula, locking plate, and allogeneic bone matrix for anterior cervical fusions after cervical discectomy for radiculopathy or myelopathy. J Neurosurg. 2001;95(1 Suppl):43-50.

17. Emery SE, Bolesta MJ, Banks MA, Jones PK. Robinson anterior cervical fusion comparison of the standard and modified techniques. Spine (Phila Pa 1976). 1994;19(6):660-3.

18. Riley Jr LH, Robinson RA, Johnson KA, Walker AE. The results of anterior interbody fusion of the cervical spine. Review of ninety-three consecutive cases. J Neurosurg. 1969;30(2):127-33. doi:10.3171/jns.1969.30.2.0127.

19. Cloward RB. The anterior approach for removal of ruptured cervical disks. J Neurosurg. 1958;15(6):602-17. doi:10.3171/jns.1958.15.6.0602.

20. Hilibrand AS, Carlson GD, Palumbo MA, Jones PK, Bohlman HH. Radiculopathy and myelopathy at segments adjacent to the site of a previous anterior cervical arthrodesis. J Bone Joint Surg Am. 1999;81(4):519-28.

21. Wu JC, Liu L, Wen-Cheng H, Chen YC, Ko CC, Wu CL, et al. The incidence of adjacent segment disease requiring surgery after anterior cervical diskectomy and fusion: estimation using an 11-year comprehensive nationwide database in Taiwan. Neurosurgery. 2012;70(3):594-601. doi:10.1227/NEU.0b013e318232d4f2.

22. Tu TH, Wu JC, Huang WC, Wu CL, Ko CC, Cheng H. The effects of carpentry on heterotopic ossification and mobility in cervical arthroplasty: determination by computed tomography with a minimum 2-year followup: Clinical article. J Neurosurg Spine. 2012;16(6):601-9. doi:10.3171/ 2012.3.SPINE11436.

23. Fay LY, Huang WC, Tsai TY, Wu JC, Ko CC, Tu TH et al. Differences between arthroplasty and anterior cervical fusion in two-level cervical degenerative disc disease. European spine journal : official publication of the European Spine Society, the European Spinal Deformity Society, and the European Section of the Cervical Spine Research Society. 2013. doi:10.1007/s00586-0133123-8.

24. Wu JC, Huang WC, Tsai HW, Ko CC, Fay LY, Tu TH, et al. Differences between 1- and 2-level cervical arthroplasty: more heterotopic ossification in 2-level disc replacement: clinical article. J Neurosurg Spine. 2012;16(6):594-600. doi:10.3171/2012.2.SPINE111066.

25. Wu JC, Huang WC, Tsai TY, Fay LY, Ko CC, Tu TH, et al. Multilevel arthroplasty for cervical spondylosis: more heterotopic ossification at 3 years of follow-up. Spine (Phila Pa 1976). 2012;37(20):E1251-9. doi:10.1097/ BRS.0b013e318265a126.

26. Maroon JC, Bost JW, Petraglia AL, Lepere DB, Norwig J, Amann C, et al. Outcomes after anterior cervical discectomy and fusion in professional athletes. Neurosurgery. 2013;73(1):103-12. doi:10.1227/01.neu.0000429843. 68836.91 discussion 12

27. Cao P, Liang Y, Gong YC, Zheng T, Zhang XK, Wu WJ. Therapeutic strategy for traumatic instability of subaxial cervical spine. Chin Med J (Engl). 2008;121(15):1364-8.
28. Maroon JC, El-Kadi H, Abla AA, Wecht DA, Bost J, Norwig J, et al. Cervical neurapraxia in elite athletes: evaluation and surgical treatment. Report of five cases. J Neurosurg Spine. 2007;6(4):356-63. doi:10.3171/spi.2007.6.4.13.

29. Meredith DS, Jones KJ, Barnes R, Rodeo SA, Cammisa FP, Warren RF. Operative and nonoperative treatment of cervical disc herniation in National Football League athletes. Am J Sports Med. 2013;41(9):2054-8. doi:10.1177/0363546513493247.

30. Feng G, Hong Y, Li L, Liu H, Pei F, Song Y, et al. Anterior decompression and nonstructural bone grafting and posterior fixation for cervical facet dislocation with traumatic disc herniation. Spine (Phila Pa 1976). 2012;37(25):2082-8. doi:10.1097/BRS.0b013e31825ee846.

31. Fehlings MG, Farhadi HF. Cervical stenosis, spinal cord neurapraxia, and the professional athlete. J Neurosurg Spine. 2007;6(4):354-5. doi:10.3171/ spi.2007.6.4.12 discussion 5.

32. Wu JC, Huang WC, Tu TH, Tsai HW, Ko CC, Wu CL, et al. Differences between soft-disc herniation and spondylosis in cervical arthroplasty: CTdocumented heterotopic ossification with minimum 2 years of follow-up. J Neurosurg Spine. 2012;16(2):163-71. doi:10.3171/2011.10.SPINE11497.

33. Mummaneni PV, Amin BY, Wu JC, Brodt ED, Dettori JR, Sasso RC. Cervical artificial disc replacement versus fusion in the cervical spine: a systematic review comparing long-term follow-up results from two FDA trials. Evid Based Spine Care J. 2012;3(S1):59-66. doi:10.1055/s-0031-1298610.

\section{Submit your next manuscript to BioMed Central and take full advantage of:}

- Convenient online submission

- Thorough peer review

- No space constraints or color figure charges

- Immediate publication on acceptance

- Inclusion in PubMed, CAS, Scopus and Google Scholar

- Research which is freely available for redistribution 